\title{
A Review of Positive Organizational Behavior: The Moderating Role of Three Contextual Factors
}

\author{
Asmaa Elsayed Belal \\ Egypt-Japan University of Science and Technology, School of International Business
}

\begin{abstract}
The concept and practice of positive organizational behavior (POB) enable a good life for individuals and organizations, and enable employees to be at their best at work. This review article examines selected representative positive state-like psychological resource capacities (efficacy, hope, optimism, resiliency, and psychological capital), and proposes a model of the contextual factors moderating the relationship between these positive capacities and individual outcomes including job satisfaction, performance, citizenship behavior and commitment. The review concludes with directions for future research.
\end{abstract}

Keywords: $P O B$, state-like psychological resource capacities; efficacy; hope; job satisfaction

\section{Introduction}

Historically, most research has focused on the negative side of work. As stated by Cameron, Dutton, and Quinn (2003), there is much more focus on negative images of violence in the workplace, organizational failings, and the failures of corporate leaders than on positive images. Additionally, organizational behavior continues to look on the dark side and to dwell on the concepts of uncertainty management, organized anarchy, disorganization theory, loosely coupled systems, and chaos theory. Seligman and Csikszentmihalyi (2000) called for building and capitalizing on the positive qualities that help individuals and societies flourish.

Luthans (2002a)conducted a computer search of contemporary literature in psychology for articles addressing negative and positive concepts. He found approximately 375000 articles on 'negatives' (i.e., mental illness, depression, anxiety, fear and anger), and only about 1000 articles on various positive concepts and capabilities of people. This reflectsthat the negative/positive publication ratio is approximately 375 to 1 (Luthans, 2002a). Maslow (1954) first introduced the term "positive psychology". In his book titled Motivation and Personality, Maslow (1954) titled the last chapter "Toward a Positive Psychology". Maslow laid out a research agenda proposing investigation of such 'new' and 'central' psychological concepts as growth, self-sacrifice, love, optimism, spontaneity, courage, acceptance, contentment, humility, kindness, and actualization of potential (as cited in Wright, 2003). 


\title{
International Conference on Research in HUMAN RESOURCE MANAGEMENT
}

\author{
March 7-9, 2019 , London-United Kingdom
}

Also, Luthans (2002a) called for identifying the nature and scope of moderating variables in POB research in order to enhance theory development. There is a paucity of research investigating various moderating variables in POB research. Therefore, the present article provides a review of the positive organizational behavior and its state-like psychological resource capacities, their association with various desired positive outcomes, as well as proposing a model incorporating three moderating variables in the relationship between the state-like capacities and the desired outcomes.

\section{Positive Organizational Behavior}

Positive organizational behavior (POB) has been defined as the study and application of positively oriented human resource strengths and psychological capacities that can be measured, developed, and effectively managed for performance improvement in today's workplace (Luthans, 2002a). There are some conditions or specific criteria for a positive psychological capacity to qualify for inclusion in $\mathrm{POB}$. These capacities must be positive and must have extensive theory and research foundations and valid measures. Moreover, they must be state-like, which would make them open to development and manageable for performance improvement. Finally, positive states that meet the POB definitional criteria are primarily researched, measured, developed, and managed at the individual, micro level (Luthans, 2002a, 2002b).

Such core POB capacities include hope, optimism, resiliency, optimism and self-efficacy (Luthans, 2002a; Luthans\& Youssef, 2004; Luthans\& Youssef, 2007). POB may contribute to positive organizational outcomes. For instance, hope, optimism, and resilience have been found to be associated with higher job satisfaction, work happiness, and organizational commitment (Luthans\& Youssef, 2007). Also, positive employee characteristics such as optimism, kindness, humor, and generosity are expected to relate to higher levels job performance (Ramlall, 2008).

The studies of Judge, Colbert and Ilies, (2004) and Wright andCropanzano (2004) argued that positiveness (as reflected in positive individual traits and positive feelings experienced at work) is important for employees' happiness and well-being. Furthermore, the benefits for the organizations are highly significant. Since positiveness, happiness, and organizational outcomes are interrelated, scholars on $\mathrm{POB}$ believe that positiveness and happiness should preoccupy not only philosophers and psychologists, but also managers and organizational leadersto consider their impact on employee and firm performance(Luthans and Youssef, 2007).

POB answers the call for the study of what goes right in organizations: identifying human strengths, producing resilience and restoration, and cultivating extraordinary individualsby focusing on positive states, traits, and processes (Cameron et al, 2003; Luthans and Youssef, 2007). States refer to the continuum from fleeting emotions to vigor, optimism, and self-efficacy. States have a malleable nature making them a critical aspect of $\mathrm{POB}$ as a result of their potential for training and development (Luthans and Church, 2002; Luthans and Youssef, 2007). Positive states represent positive psychological resources that can give an advantage in the workplace. Many positive states 


\title{
International Conference on Research in HUMAN RESOURCE MANAGEMENT
}

\author{
March 7-9, 2019 , London-United Kingdom
}

have been linked to positive outcomes at work(Kluemper, Little, and DeGroot, 2009). Traits, on the other hand, are relatively enduring, stable, and develop over one's life span. Traits include various aspects of personality such as core self-evaluation (Judge, Locke, Durham \&Kluger, 1998). Given their more stable nature, traits can be important in the development of states (Luthans and Youssef, 2007) as well as in determining individual fit within organizations (Kristof-Brown, Zimmerman, and Johnson, 2005). The processes of communication, forgiveness, compassion, and thriving involve courses of action that facilitate positive outcomes (as cited in Luthans and Youssef, 2007).

\section{Positive Traits}

\section{The big five personality traits}

The Big Five traits have been found to be related to individual-level outcomes such as happiness, physical and psychological health, spirituality, and identity; interpersonal-level outcomes such as quality of relationships with peers, family, and organizational- or social-level outcomes such as occupational choice, satisfaction, performance, and community involvement (Ozer\& BenetMartinez, 2006). These personality traits have also been found to be positively related to cultural intelligence (Ang, Van Dyne, \&Koh, 2006), and satisfaction with teams (Peeters, Rutte, van Tuijl, \&Reymen, 2006) and negatively associated with undesirable outcomes such as burnout (Bakker, van der Zee, Lewig, \& Dollard, 2006).

\section{Core Self-Evaluations}

Another classification of positive traits that have an effect on work-related outcomes comes from Judge and colleagues' research on the four core self-evaluations of self-esteem, generalized selfefficacy, locus of control, and emotional stability. These traits have been shown to be significant positive predictors of goal setting, motivation, performance, job and life satisfaction, and other desirable outcomes (Erez\&Isen, 2002; Judge \& Bono, 2001; Judge,VanVianen, \& De Pater, 2004). In essence, the higher an individual's self-evaluations, the more positive the person's self-regard and the more goal self-concordance is expected to be experienced. Those with goal self-concordance are intrinsically motivated to pursue their goals for their intrinsic value. Because of the value congruence of the goals, they generate higher intrinsic motivation and trigger higher performance and satisfaction (Judge, Bono, Erez, \& Locke, 2005). Higher self-evaluations are also negatively associated with undesirable outcomes such as burnout (Best, Stapleton, \& Downey, 2005).

\section{Positive State-Like Capacities}

Unlike positive traits, which are characterized by relative stability over time and applicable across situations, positive state-like capacities are relatively more malleable and thus are open to change and development (Luthans, 2002a, 2002b; Luthans\& Youssef, 2007). This developmental 


\title{
International Conference on Research in HUMAN RESOURCE MANAGEMENT
}

\author{
March 7-9, 2019 , London-United Kingdom
}

characteristic of positive psychological resource capacities is particularly relevant to today's workplace characterized by speed and flexibility in growth and development and these have to match the realities of a fast-paced, unpredictable environment (Luthans\& Youssef, 2007). Consequently, positive psychological capacities open to investment and development (Luthans, Avey, Avolio, Norman, \& Combs, 2006; Luthans\& Youssef, 2007) may provide organizations with an unprecedented potential source of competitive advantage through their people.

When referring to positive capacities in $\mathrm{POB}$ the term state-like is used to reflect that they lie along a continuum with traits (Luthans, 2002a, 2002b; Luthans\&Youssef, 2007). More specifically, on one end of the continuum as depicted by Luthans, Youssef (2007) would be positive states that are very changeable representing momentary feelings (e.g., pleasure, positive moods, and many definitions of happiness). Next along the continuum would be the state-like positive psychological resource capacities that are still relatively malleable and open to development (e.g., efficacy, hope, optimism, and resilience). These state-like capacities are followed on the continuum by the trait-like constructs that are relatively stable and difficult to change (e.g., Big Five personality dimensions, core selfevaluations) (Luthans\&Youssef, 2007).

On the other extreme end of this continuum would be positive traits that are very stable, fixed, very difficult to change, and commonly referred to as being "hard wired" (e.g., intelligence, talents, and positive heritable characteristics). In other words, at least in the short run, the state-like psychological capacities may be somewhat stable and not change with each momentary situation. However, the term state likealso infers that they are relatively less fixed than personality or selfevaluation traits(Luthans and Youssef, 2007).

\section{Self-Efficacy as a State-Like Psychological Resource Capacity}

Building on Bandura's (1986, 2001) social cognitive theory, Stajkovic and Luthans (1998) define selfefficacy in the workplace as one's confidence about his or her abilities to mobilize the motivation, cognitive resources, and courses of action needed to successfully execute a specific task within a given context. Self-efficacy represents the best fit with all the criteria to be selected for inclusion in POB (Luthans, 2002a). Several factors are unique to self-efficacy and make it particularly relevant to POB. First, self-efficacy has the most established theoretical foundation and the most extensive research support (Luthans and Youssef, 2007). Second, although hope, optimism, and resiliency have been conceptualized, measured, and tested both as traits and as states, self-efficacy has been primarily supportedand measured (Maurer \& Pierce, 1998; Parker, 1998) as a state(Luthans and Youssef, 2007). Its state-like nature is manifested not only in its developmental nature over time but also in its domain specificity. Having efficacy in one domain is not necessarily transferable to other domains, whereas lacking efficacy in some contexts does not preclude being efficacious in others (Bandura, 2001). 


\title{
International Conference on Research in HUMAN RESOURCE MANAGEMENT
}

\author{
March 7-9, 2019 , London-United Kingdom
}

Third, the relationship between self-efficacy and numerous work-related performance dimensionsis highly established. These desirable outcomes include work attitudes across cultures (Luthans, Zhu, \&Avolio, 2006), leadership effectiveness (Chemers,Watson, \& May, 2000; Luthans, Luthans, Hodgetts, \&Luthans, 2001), moral or ethical decision making (May, Chan, Hodges, \&Avolio, 2003), participation (Lam, Chen, \&Schaubroeck, 2002), and learning (Ramakrishna, 2002). The findings of Bandura \& Locke, 2003; Stajkovic\&Luthans, 1998) also support that self-efficacy is strongly related to work-related performance.

\section{Hope as a State-Like Psychological Resource Capacity}

Snyder, Irving, and Anderson (1991) define hope as a positive motivational state that is based on an interactively derived sense of successful (1) agency (goal-directed energy) and (2) pathways (planning to meet goals). Hope capitalizes on an individual's self-initiated, goal-directed motivations and behaviors. However, hope focuses on a different set of mechanisms through which goals are accomplished (Snyder, 2002).

According to Snyder (2002), one of these mechanisms or ingredients of hope is the sense of agency or internalized control that creates the determination and motivation (willpower) to accomplish one's goals. A second component is the process through which alternative pathways and contingency plans are created and adapted to achieve goals and overcome obstacles (waypower). Finally, hope involves the quality of goals being set and the mechanisms through which increasingly challenging goals are selected, approached, accomplished, and changed if necessary in light of additional evidence and new realities of the situation (Snyder, 2002).

Emerging research supports the relevance of hope to the workplace and its impact on performance outcomes. For example, recent empirical studies support a positive relationship between employee hope and job performance, job satisfaction, work happiness and organizational commitment (Luthans and Youssef, 2007), between entrepreneurs' hope and their satisfaction with business ownership (Jensen \&Luthans, 2002), and between organizational leaders' hope and the profitability of their units and the satisfaction and retention of their employees (Peterson \&Luthans, 2003).

\section{Optimism as a State-Like Psychological Resource Capacity}

Optimism can be viewed as an attributional style that explains positive events through personal, permanent, and pervasive causes and negative events through external, temporary, and situationspecific ones(Luthans and Youssef, 2007). On the other hand, pessimism externalizes positive events and attributes them to temporary and situation-specific causes while internalizing negative events and attributing then to permanent and pervasive ones (Peterson \& Steen, 2002). As a result of these attributional or explanatory style differences, optimists build positive expectancies that motivate their goal pursuit and approach coping behavior in the future, whereas pessimists are hindered by self-doubt and negative expectancies (Carver \&Scheier, 2002). 


\title{
International Conference on Research in HUMAN RESOURCE MANAGEMENT
}

\author{
March 7-9, 2019 , London-United Kingdom
}

Particularly relevant to the inclusion of optimism in POB is its supported positive relationship with performance in various life domains (Peterson \& Barrett, 1987; Prola\& Stern, 1984), especially the workplace (Luthans, Avolio, Walumbwa, \& Li 2005; Luthans and Youssef, 2007). For example, optimism has been found to predict higher performance in sales, and leadership (Chemerset al., 2000; Schulman, 1999; Wunderley, Reddy, \&Dember, 1998). Optimismhas also been related to job satisfaction, job performance, work happiness andorganizational commitment (Luthans and Youssef, 2007; Kluemper, Little, and DeGroot, 2009).

\section{Resiliency as a State-Like Psychological Resource Capacity}

Luthans (2002b) defines resiliency as the capacity to rebound or bounce back from adversity, conflict, failure, or even positive events, progress, and increased responsibility. The POB perspective on resilience indicates that it is a learnable capacity that can be developed in most people (Masten, 2001) and measured as state like (Luthans et al., 2005; Wagnild\& Young, 1993).

POB resiliency allows adversities and setbacks to be viewed as opportunities for learning, growth, and development. It engages creative and flexible adaptive mechanisms, guided by ethical values and strong belief systems, toward the achievement of personally and organizationally meaningful goals (Luthans and Youssef, 2007).

This type of resilience has been supported as a predictor of work-related outcomes including job performance, job satisfaction, work happiness, organizational commitment and shown to be open to development and management in the workplace (Luthans,Avey, et al., 2006; Luthans and Youssef, 2007; Luthans, Vogelgesang, \& Lester, 2006; Vickers \&Kouzmin, 2001; Waite \& Richardson, 2004).

\section{Psychological Capital or PsyCap}

Luthanset al. (2006) argue that hope, self-efficacy, optimism, and resiliency contribute more to our learning when combined. PsyCapcomprises a higher-order construct that reflects the combination of these fourlower-order constructs. This PsyCap is comprehensively defined as an individual's positive psychological state of development that is characterized by: (1) having confidence (selfefficacy) to take on and put in the necessary effort to succeed at challenging tasks; (2) making a positive attribution (optimism) about succeeding now and in the future; (3) persevering toward goals and, when necessary, redirecting paths to goals (hope) in order to succeed; and (4) when affected by problems and adversity, sustaining and bouncing back and even beyond (resiliency) to attain success (Luthans\&Youssef, 2007).It has been shown to relate to performance and satisfactionin the workplace (Luthanset al., 2006) as well as organizational citizenship behavior (Avey, Wernsing and Luthans, 2008). 


\title{
International Conference on Research in HUMAN RESOURCE MANAGEMENT
}

\author{
March 7-9, 2019 , London- United Kingdom
}

\section{The role of contextual factors}

Consistent with Luthans' call (2002a)for enhanced theory development in identifying the nature and scope of moderating variables in POB research, the proposed model in figure one incorporates three moderating variables in the relationship between state-like capacities and the desired outcomes. These will be discussed next.

\section{Leadership Style}

Authentic leadership is defined as a process that draws fromboth positive psychological capacities and a highly developedorganizational context, which results in both greater self-awarenessand selfregulated positive behaviors on the part of leaders andassociates, fostering positive selfdevelopment (Luthans\&Avolio, 2003).

Authentic leaders are developed through the concerted contributions of life experiencesand stable personality traits, positive psychological states, and a supportive, developmental organizational climate. Authentic leaders in turn engage in behaviors that build their associates' authentic leadership and followership capacities and that are transparent, moral, ethical, and future oriented (Gardner, Avolio, Luthans, May, \&Walumbwa, 2005).

For example, authentic leaders'self-transcendent values, positive cognitions, and positive otherdirected emotion may interactively promote positive, self-transcendent organizational behaviors. Also, individuals can be persuaded by respected and/or relevant othersto be more confident. For example, a respected leader informing one of his or her employees that $\mathrm{s} / \mathrm{he}$ believes this associate has the capability to accomplish a given task. This, coupled with providing feedback to the employee that progress is being made, would both be expected to build the self-efficacy of the subordinate (Luthans, Avey, Avolio and Peterson, 2010).

However, a leader's authenticity and ability to exhibit self-transcendent behaviors are also deeply rooted in self-awareness, person-role congruence, and self-concordant goals and the ability to authentically articulate such a perspective in ways that are inspiring and constructive to oneself and others (Shamir \&Eilam, 2005; Sparrowe, 2005). In other words, authentic leadership and its development can offer another untapped positive resource that can result in upward spirals of positive change across various organizational levels.Based on the previous argument the following proposition can be made:

Proposition one: Authentic leadership moderates the relationship between state-like capacities and desired work-related outcomes.

\section{Organizational Culture}

The promotion of a flexibility-oriented culture in which leaders provide a context for cooperation and support produces positive effects on followers and organizations, such as job satisfaction (Azanza, Moriano and Molero, 2013).Companies with a positive organizational culture focus on rewarding employees and creating an environment where employees can develop, grow and operate 


\title{
International Conference on Research in HUMAN RESOURCE MANAGEMENT
}

\author{
March 7-9, 2019 , London-United Kingdom
}

at their full potential (Parent and Lovelace, 2015). According to Malik (2013), cultures with optimistic explanatory styles are typically highly motivated, task oriented, socially interactive and supportive, resilient, able to persevere, less prone to stress and depression, able to make effective decisions, and solution focused. With this range of positive organizational influences, taking the time to adopt optimistic explanatory styles within an organization would likely produce efficient, effective and successful work forces. Based on the discussion above it can be expected that a positive culture will promote the expression of employees' psychological capacities, hence, the following proposition:

Proposition two: Positive organizational culture moderates the relationship between state-like capacities and desired work-related outcomes.

Job Characteristics

The literature on the moderating role of job characteristics (including autonomy, skill variety, skill identity, skill significance and feedback according to Hackman and Lawler, 1976 model)in the relationship between the psychological capacities and the desired work-related outcome is still scarce. The researcher could not identify other studies examining this relationship except for the study of Chaudhry, Maurice and Haneefuddin (2015) which found that the characteristics of the assigned job have a significant influence on the affective statesof employees which, in turn, shape their work related outcomes including job satisfaction, commitment to organization, citizenship behavior and counterproductive work behavior. Therefore, the following proposition can be made:

Proposition three: Job characteristics moderate the relationship between state-like capacities and desired work-related outcomes.

Figure 1: Proposed Model

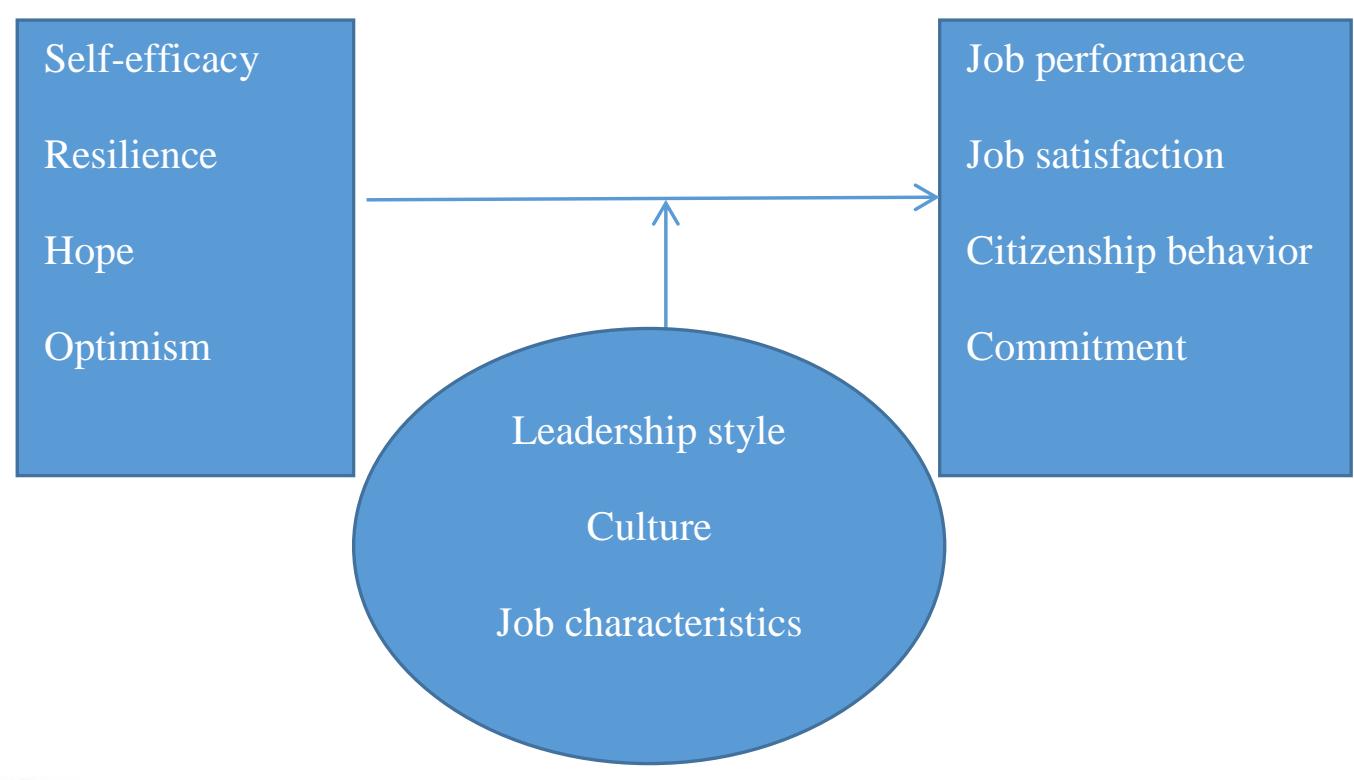




\section{International Conference on Research in HUMAN RESOURCE MANAGEMENT}

March 7-9, 2019 , London- United Kingdom

\section{Directions for Future Research}

Future research needs to examine the impact ofother potential positive psychological resource capacities such as wisdom or courage (Luthans and Youssef, 2007). Also,future studies need to testwhether the findings of regarding POB in U.S-based organizations will hold across cultures (Luthans and Youssef, 2007).

The positive approach in general includes both psychological states and traits.A richer understanding of the stability of all positive constructs using longitudinal research would enable both scholars andpractitioners to determine which capacities are indeed open to development and which are moresuitable for selection (Avey, Luthans and Mhatre, 2008). Another use of longitudinal designs in future research could be testing theory-driven hypotheseson the extent to which POB constructs are attributable to the person and how much is attributable tothe context. Also, future research could benefit from the inclusion of other moderating variables other than the ones mentioned in this review. 


\title{
International Conference on Research in HUMAN RESOURCE MANAGEMENT
}

\author{
March 7-9, 2019 , London- United Kingdom
}

\section{References}

Ang, S., Van Dyne, L., \&Koh, C. (2006). Personality correlates of the four-factor model of cultural intelligence. Group \& Organization Management, 31: 100-123.

Avey, J. B., Wernsing, T. S., \&Luthans, F. (2008). Can positive employees help positive organizational change? Impact of psychological capital and emotions on relevant attitudes and behaviors. The Journal of Applied Behavioral Science, 44, 48-70.

Avey, J. B., Luthans, F., \&Mhatre, K. H. (2008).A call for longitudinal research in positive organizational behavior.Journal of Organizational Behavior, 29 (5), 705-711

Azanza, G., Moriano, J. A., \&Molero, F. (2013). Authentic leadership and organizational culture as drivers of employees' job satisfaction. Journal of Work and Organizational Psychology, 29, 45-50 Bakker, A. B., van der Zee, K. I., Lewig, K. A., \& Dollard, M. F. (2006). The relationship between the Big Five personality factors and burnout: A study among volunteer counselors. Journal of Social Psychology, 146(1): 31-50.

Bandura, A. (2001). Social cognitive theory: An agentic perspective. Annual Review of Psychology, 52: 1-26.

Bandura, A. (1986). Social foundations of thought and action: A social cognitive theory. Englewood Cliffs, NJ:Prentice Hall.

Bandura, A., \& Locke, E. (2003). Negative self-efficacy and goal effects revisited. Journal of Applied Psychology, 88: 87-99.

Best, R. G., Stapleton, L. M., \& Downey, R. G. (2005). Core self-evaluations and job burnout: The test of alternative models. Journal of Occupational Health Psychology, 10: 441-451.

Cameron, K., Dutton, J., \& Quinn, R. (2003).Positive organizational scholarship. Chapter one, San Francisco: Berrett-Koehler.

Chaudhry, I., S., Maurice, J., G., \&Haneefuddin, M. (2015). Impact of job characteristics on employee emotions and Work-related outcomes in Pakistan.International Journal of Business and Management, 10 (8).

Chemers, M. M., Watson, C. B., \& May, S. T. (2000). Dispositional affect and leadership effectiveness: A comparison of self-esteem, optimism, and efficacy. Personality and Social Psychology Bulletin, 26: 267-277.

Carver, C., \&Scheier, M. (2002).Optimism. In C. R. Snyder \& S. Lopez (eds.), Handbook of positive psychology: 231-243. Oxford, UK: Oxford University Press.

Erez, A., \&Isen, A. M. (2002).The influence of positive affect on the components of expectancy motivation.Journal of Applied Psychology, 87, 1055-1067.

Gardner, W. L., Avolio, B. J., Luthans, F., May, D. R., \&Walumbawa, F. O. (2005). Unlocking the mask: A look at the process by which authentic leaders impact follower attitudes and behaviors. The Leadership Quarterly, 15, 801-823 


\section{International Conference on Research in HUMAN RESOURCE MANAGEMENT}

\section{March 7-9, 2019 , London- United Kingdom}

Hackman, J. R., \& Oldham, G. R. (1976). Motivation through the design of work: Test of a theory. Organizational Behavior and Human Performance, 16, 250-279.

Jensen, S. M., \&Luthans, F. (2000).The impact of hope in the entrepreneurial process: Exploratory research findings. Decision Sciences Institute Conference Proceedings, San Diego, CA.

Judge, T. A., \& Bono, J. E. (2001). Relationship of core self-evaluations traits-self-esteem, generalized self-efficacy, locus of control, and emotional stability-with job satisfaction and job performance: A meta-analysis. Journalof Applied Psychology, 86: 80-92.

Judge, T. A., Bono, J. E., Erez, A., \& Locke, E. A. (2005). Core self-evaluations and job and life satisfaction: The role of self-concordance and goal attainment. Journal of Applied Psychology, 90: 257-268.

Judge, T. A., Van Vianen, A. E. M., \& De Pater, I. E. (2004). Emotional stability, core self-evaluations, and job outcomes: A review of the evidence and an agenda for future research. Human Performance, 17: 325-346.

Judge, T. A., Locke, E. A., Durham, C. C., \&Kluger, A. N. (1998). Dispositional effects on job and life satisfaction: The role of core evaluations. Journal of Applied Psychology, 83: 17-34.

Judge, T. A., Colbert, J. E., \&llies, R. (2004). Intelligence and leadership: A quantitative review and test of theoretical propositions. Journal of Applied Psychology, 89: 542-552.

Kluemper, D., Little, L.M., \&DeGroot, T. (2009). State or trait: Effects of state optimism on job-related outcomes. Journal ofOrganizational Behavior, 30(2), 209 -31.

Kristof-Brown, A.L., Zimmerman, R.D., \& Johnson, E.C. (2005). Consequences of Individual's fit at work: A meta-analysis of person-job, person-organization, person-group and person-supervisor fit. Personnel Psychology, 58(2), 281-342.

Lam, S., Chen, X., \&Schaubroeck, J. (2002). Participative decision making and employee performance in different cultures: The moderating effects of allocentrism/idiocentrism and efficacy. Academy of Management Journal, 45: 905-914.

Luthans, F., Luthans, K., Hodgetts, R., \&Luthans, B. (2001). Positive approach to leadership (PAL): Implications for today's organizations. Journal of Leadership Studies, 8(2): 3-20.

Luthans, F. (2002a). Positive organizational behavior: Developing and managing psychological strengths. Academy of Management Executive, 16(1): 57-72.

Luthans, F. (2002b). The need for and meaning of positive organizational behavior. Journal of Organizational Behavior, 23: 695-706.

Luthans, F., \& Church, A. (2002). Positive organizational behavior: developing and managing psychological strengths. Academy of Management Executive,16(1), 57-75.

Luthans, F., \&Avolio, B. J. (2003). Authentic leadership: A positive developmental approach. In K. S. Cameron, J. E. Dutton, \& R. E. Quinn (Eds.), Positiveorganizational scholarship: Foundations of a new discipline (pp. 241-261). San Francisco, CA: Barrett-Koehler 


\section{International Conference on Research in HUMAN RESOURCE MANAGEMENT}

\section{March 7-9, 2019 , London- United Kingdom}

Luthans, F., \& Youssef, C. M. (2004). Human, social, and now positive psychological capital management: Investing in people for competitive advantage. Organizational Dynamics, 33(2): 143160.

Luthans, F., Avolio, B. J., Walumbwa, F. O., \& Li, W. (2005). The psychological capital of Chinese workers: Exploring the relationship with performance. Management and Organization Review, 1: 247-269.

Luthans, F., Zhu, W., \&Avolio, B. J. (2006).The impact of efficacy on work attitudes across cultures.Journal of World Business, 41: 121-132.

Luthans, F., Vogelgesang, G. R., \& Lester, P. B. (2006).Developing the psychological capital of resiliency.Human Resource Development Review, 5(1): 25-44.

Luthans, F., Avey, J. B., Avolio, B. J., Norman, S. M., \& Combs, G. J. (2006). Psychological capital development: Toward a micro-intervention. Journal of Organizational Behavior, 27: 387-393.

Luthans, F., \& Youssef, C. M. (2007). Emerging positive organizational behavior. Journal of Management, 33: 321-349.

Luthans, F., Avey, J. B., Avolio, B. J., \& Peterson, S. J. (2010). The development and resulting performance impact of positive psychological capital. Human Resource Development Quarterly, 21 (1), 41-67.

Malik, A. (2013). Efficacy, hope, optimism and resilience at workplace-positive organizational behavior.International Journal of Scientific and Research Publications, 3, (10)

Masten, A. S. (2001). Ordinary magic: Resilience process in development. American Psychologist, 56: 227-239.

Maurer, T. J., \& Pierce, H. R. (1998).A comparison of Likert scale and traditional measures of selfefficacy.Journal of Applied Psychology, 83: 324-329.

May, D., Chan, A., Hodges, T., \&Avolio, B. (2003). Developing the moral component of authentic leadership.Organizational Dynamics, 32: 247-260.

Ozer, D. J., \& Benet-Martinez, V. (2006).Personality and the prediction of consequential outcomes.Annual Review of Psychology, 57: 401-421.

Parent, J. D., \& Lovelace, K. J. (2015).The impact of employee engagement and a positive organizational culture on an individual's ability to adapt to change.Eastern Academy of Management Proceedings: Organization Behavior and Theory Track

Parker, S. (1998).Enhancing role breadth self-efficacy: The roles of job enrichment and other organizational interventions.Journal of Applied Psychology, 6: 835-852.

Peeters, M. A., Rutte, C. G., van Tuijl, H. F., \&Reymen, I. M. (2006). The Big Five personality traits and individual satisfaction with the team.Small Group Research, 37: 187-211.

Peterson, C., \& Barrett, L. (1987).Explanatory style and academic performance among university freshmen.Journal of Personality and Social Psychology, 53: 603-607. 


\section{International Conference on Research in HUMAN RESOURCE MANAGEMENT}

\section{March 7-9, 2019 , London- United Kingdom}

Peterson, C., \& Steen, T. (2002).Optimistic explanatory style. In C. R. Snyder \& S. Lopez (Eds.), Handbook of positive psychology: 244-256. Oxford, UK: Oxford University Press.

Peterson, S. J., \&Luthans, F. (2003).The positive impact and development of hopeful leaders.Leadership and Organization Development Journal, 24(1): 26-31.

Prola, M., \& Stern, D. (1984).Optimism about college life and academic performance in college.Psychological Reports, 55: 347-350.

Ramakrishna, H. (2002). The moderating role of updating climate perceptions in the relationship between goal orientation, self-efficacy, and job performance.Human Performance, 15: 275-297

Ramlall, S. J. (2008). Enhancing employee performance through positive organizational behavior.Journal of Applied Social Psychology, 38, 1580-1600

Schulman, P. (1999). Applying learned optimism to increase sales productivity. Journal of Personal Selling and Sales Management, 19: 31-37.

Seligman, M. E. P., \&Csikszentmihalyi, M. (2006).Positive psychology.American Psychologist, 55, 514.

Shamir, B., \&Eilam, G. (2005). What's your story? A life-stories approach to authentic leadership development.Leadership Quarterly, 16: 395-417.

Snyder, C. R. (2002). Hope theory: Rainbows in the mind. Psychological Inquiry, 13: 249-276.

Snyder, C. R., Irving, L., \& Anderson, J. (1991). Hope and health: Measuring the will and the ways. In C. R. Snyder \& D. R. Forsyth (Eds.), Handbook of social and clinical psychology: 285-305. Elmsford, NY: Pergamon.

Sparrowe, R. T. (2005). Authentic leadership and the narrative self.Leadership Quarterly, 16: 419439.

Stajkovic, A. S. \&Luthans, F. (1998). Social cognitive theory and self-efficacy: Going beyond traditional motivational and behavioral approaches. Organizational Dynamics, 26, 62-74.

Vickers, M. H., \&Kouzmin, A. (2001).Resilience in organizational actors and rearticulating voice.Public Management Review, 3(1): 95-119

Wagnild, G., \& Young, H. (1993).Development and psychometric evaluation of the Resiliency Scale.Journal of Nursing Measurement, 1(2): 165-178.

Waite, T. P., \& Richardson, G. (2004).Determining the efficacy of resiliency training in the work site.Journal of Allied Health, 33: 178-183.housand Oaks, CA: Sage.

Wright, T. A., \&Cropanzano, R. (2004).The role of psychological well-being in job performance.Organizational Dynamics, 33: 338-351.

Wright, T. A. (2003). Positive organizational behavior: An idea whose time has truly come. Journal of Organizational Behavior, 24: 437-442.

Wunderley, L. J., Reddy, W. P., \&Dember, W. N. (1998). Optimism and pessimism in business leaders.Journal of Applied Social Psychology, 28: 751-760. 